\title{
Intraembryonic Coelom
}

National Cancer Institute

\section{Source}

National Cancer Institute. Intraembryonic Coelom. NCI Thesaurus. Code C34195.

A cavity located in the lateral plate mesoderm in the conceptus, which appears during the third week of development, and which eventually forms the pleuropericardial-peritoneal cavity. 